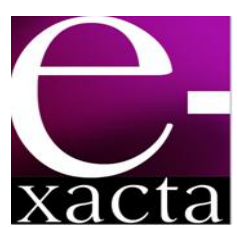

ISSN: 1984-3151

\title{
SEARCH ClASS: SISTEMA PARA GERENCIAMENTO DE ROTAS EM UNIVERSIDADES POR MEIO DE MÓDULOS GPS E PONTOS DE LOCALIZAÇÃO NÃO MAPEADOS PELO GOOGLE
}

\author{
SEARCH ClasS: ROUTES MANAGEMENT SYSTEM IN UNIVERSITIES \\ THROUGH GPS MODULES AND POINTS LOCATION NOT MAPPED BY \\ GOOGLE
}

\author{
Giovanni Amormino da Silva Júnior ${ }^{1}$; Ana Cristina Pereira Soares ${ }^{2}$; Moisés Henrique \\ Ramos Pereira ${ }^{3}$; Eduardo Habib Bechelane Maia ${ }^{4}$ \\ 1 Graduado em Ciência da Computação. UniBH, 2014. \\ Programador ABA Júnior II da HR Tecnologia. Belo \\ Horizonte, MG. gigio ir@hotmail.com. \\ 2 Graduada em Ciência da Computação. UniBH, 2014. \\ Desenvolvedora Web da Calebe Design. Belo Horizonte, \\ MG. anacristinadev@gmail.com. \\ 3 Mestre em Modelagem Matemática e Computacional. \\ CEFET-MG, 2012. Professor do Centro Universitário de \\ Belo Horizonte - UniBH. Belo Horizonte, MG. \\ moises.ramos@prof.unibh.br. \\ 4 Mestre em Ciência da Computação. UFMG, 2006. Professor \\ do Centro Federal de Educação Tecnológica de Minas \\ Gerais. Divinópolis, MG. eduardohabib@gmail.com.
}

Recebido em: 30/03/2015 - Aprovado em: 26/05/2015 - Disponibilizado em: 30/05/2015

RESUMO: O avanço das tecnologias móveis trouxe aos usuários a possibilidade de acesso às informações de qualquer lugar a partir de uma rede sem fio. Tais facilidades fazem com que os usuários dessas tecnologias sejam mais exigentes com as aplicações desenvolvidas. Considerando o problema encontrado pelos alunos em localizar suas respectivas salas em cada horário, atrelado ao problema de localização das pessoas dentro do campus de uma universidade, o presente artigo busca, por meio da avaliação de resultados, apresentar uma ferramenta capaz de solucionar ambos os problemas e apresentar a seus usuários o menor caminho entre o local que eles acessaram o aplicativo e o local onde a turma deles está alocada para aquela aula. Neste trabalho, tem-se uma descrição detalhada da modelagem e da implementação do aplicativo. Resultados experimentais são apresentados e promovem a aplicação como promissora no contexto modelado.

PALAVRAS-CHAVE: Tecnologias Móveis. Mapeamento de Rotas. Localização de Salas.

ABSTRACT: The advancement of mobile technologies has brought users the possibility to access information from anywhere from a wireless network. Such features make users of these technologies are developed with the most demanding applications. Considering the problem encountered by students in finding their respective rooms each turn, linked to the problem of location of people inside in an university campus, this paper aims, through the evaluation of results, present a tool capable of solving both problems and provide its users with the shortest path between the location they accessed the application and where the class of them is allocated to that class. In this paper, there is a description detailing the modeling and the application deployment. Experimental results are presented and promoted as a promising application in modeling context.

KEYWORDS: Mobile Technologies. Route Mapping. Location Classroom. 


\section{INTRODUÇÃo}

Com o desenvolvimento e evolução das redes sem fio, surge um novo paradigma da computação voltado, principalmente, à mobilidade do acesso aos dados: trata-se da computação móvel que surge como uma quarta revolução na computação, além dos grandes centros de processamentos de dados na década de 60 , do surgimento dos terminais na década de $70 \mathrm{e}$ das redes de computadores na década de 80 (MATHEUS; LOUREIRO, 1998). O paradigma da computação móvel amplia o conceito tradicional de computação distribuída devido ao auxílio das comunicações sem fio. Esse tipo de comunicação eliminou a necessidade de que o usuário mantenha-se conectado a uma infraestrutura fixa e/ou estática (MATHEUS; LOUREIRO, 1998; FIGUEIREDO; NAKAMURA, 2003).

Para que um dispositivo se enquadre na definição de computação móvel, ele deve ser capaz de trocar informações por meio da rede, de realizar o devido processamento e de ser transportado facilmente por seus usuários (FIGUEIREDO; NAKAMURA, 2003). Com o intuito de implementar uma aplicação sobre um sistema robusto que possa promover essas premissas, escolheu-se a plataforma para tecnologia móvel Android que possui um pacote com programas para celular, sistema operacional, middleware, aplicativos e interface com o usuário. Essa plataforma foi construída com a intenção de se permitir tirar total proveito dos recursos de um aparelho móvel em cada aplicativo desenvolvido (PEREIRA; LOURENÇO, 2009; BALDI, 2011; LECHETA, 2013). Além disso, por se inserir no contexto de código aberto, pode adaptarse mais facilmente a novas tecnologias, fazendo com que a plataforma continue evoluindo conforme a necessidade de aplicativos inovadores (PEREIRA; LOURENÇO, 2009; LECHETA, 2013).
Com o objetivo de se obter a posição instantânea do usuário, foi utilizado o recurso de GPS (do inglês, Global Positioning System). Segundo Bernardi e Landim (2002), o GPS é um sistema que permite aos usuários determinar as posições de acordo com latitude, longitude e altura geométrica ou elipsoidal em função das coordenadas cartesianas $X, Y$ e $Z$ em relação ao centro de massa da Terra, conforme esboçado na FIG. 1. Nos sistemas de posicionamento presentes em dispositivos móveis, o próprio dispositivo é responsável por determinar sua localização através de uma rede de transmissores que emitem um sinal utilizado para identificação da localização (CORREIA, 2004).

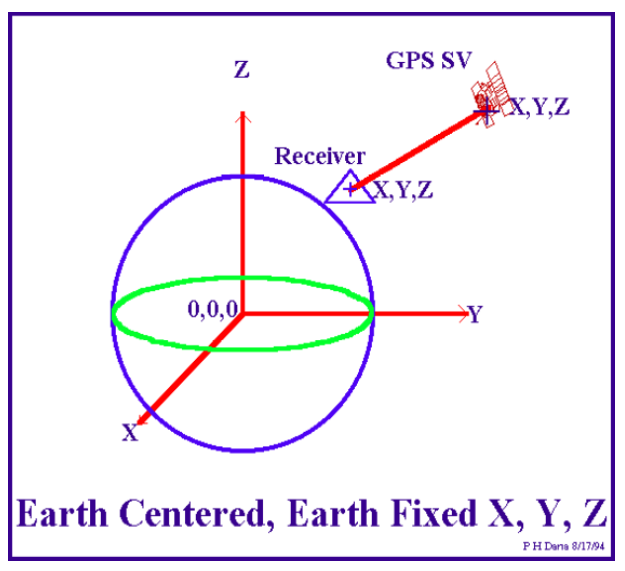

Figura 1 - Posicionamento GPS baseado no centro de massa da Terra.

Fonte: BERNARDI; LANDIM, 2002.

Junto ao desenvolvimento da computação móvel, surgiu a necessidade de integração com informações de localização. Surgiram, então, serviços que integram a posição ou localização de um dispositivo móvel com outras informações, os chamados Sistemas Baseados em Localização (LBS, do inglês Location-Based Services), criados por volta da década de 70 após a concepção e implantação do GPS pelo Departamento de Defesa dos Estados Unidos (CORREIA, 2004).

Estes são serviços que integram a localização de um dispositivo móvel com outras informações. Essa 
integração é feita de forma a proporcionar rapidez na consulta baseada em georreferenciamento, exibindo para o usuário a localização de serviços próximos a ele (BALDI, 2011; BALTZAN; PHILLIPS, 2012). Segundo Baldi (2011), os serviços de localização se definem na localização do dispositivo móvel e as informações que forem necessárias para se localizar os serviços de interesse do usuário existentes em uma região (FIORESE, 2005).

A integração de funcionalidades como o GPS aos aparelhos móveis se deu pela expansão das necessidades de seus usuários. Contudo, tais funcionalidades devem ser adaptadas a outros contextos para passar aos usuários o maior número de informações relevantes possíveis (BALDI, 2011).

Segundo Correia (2004), a crescente mobilidade proporcionada pela evolução da computação móvel tem feito com que seus usuários fiquem mais exigentes. Ainda segundo o autor, estes usuários desejam aplicações inteligentes, que personalizem as informações de forma que tais usuários consigam tirar proveito de todo o ambiente ao seu redor. Essa exigência torna fundamental a compreensão dos novos problemas e a busca por soluções para os desafios desta nova área do desenvolvimento tecnológico (CORREIA, 2004).

Um problema bastante comum que se enquadra neste cenário é a dificuldade de orientação de alunos, principalmente calouros, dentro de uma universidade ao início de cada semestre letivo. Saber onde serão ministradas as aulas a cada horário pode se tornar uma tarefa bastante desagradável considerando fatores como: desconhecimento do campus e da localização dos prédios que o compõe, a falta de mapas que possam auxiliar essa tarefa, turmas mescladas e/ou diferentes, entre outros.

Considerando o problema supracitado, este artigo tem por objetivo o desenvolvimento de uma ferramenta que auxilie os alunos e professores na busca por suas salas em seus respectivos prédios dentro da universidade. Os objetivos específicos são:

- Avaliar as necessidades de um software que possua este fim;

- Desenvolver um software baseado nas características avaliadas que mostre o menor caminho entre a posição atual do usuário e o ponto de destino;

- Apresentar os resultados obtidos a partir do desenvolvimento do software.

Nas seções subsequentes, este artigo está assim organizado: (i) a segunda seção aborda alguns sistemas que possuem alguns aspectos similares ao sistema proposto; (ii) a terceira trata da modelagem do sistema, detalhando os objetivos e as funcionalidades de cada um de seus módulos; (iii) a seção subsequente mostra os resultados obtidos a partir da implantação do sistema em uma universidade; (iv) a quinta seção aborda os testes realizados e os resultados obtidos; (v) e, finalmente, estão a conclusão, os trabalhos futuros, os agradecimentos e as referências.

\section{TRABALHOS RELACIONADOS}

Embora muitos aplicativos e sistemas, comerciais ou acadêmicos, possam ter propostas e objetivos similares, foram escolhidos dois aplicativos populares e renomeados no mercado para estudo de suas características e seus diferenciais objetivando adaptar estes diferenciais ao sistema proposto.

\subsection{Google MAPS}

Além de ser um dos mais populares aplicativos móveis de criação de rotas, ele contribuiu na criação deste 
tipo de sistema em todo o mundo. Além de possuir suporte tanto Web quanto mobile, possui também uma API (Interface de Programação de Aplicativos) disponibilizada a fim de integrar as ferramentas de mapas para diversas outras aplicações (CASTRO; TEDESCO, 2014).

O aplicativo foi avaliado por mais de quatro milhões e 500 mil pessoas e possui uma média de 4.3 estrelas na Google Play. Ele permite a visualização do fluxo de tráfego nas vias, visualizar a pontos específicos e seus pontos favoritos, ter variados tipos de mapas diferentes e obter recomendação de rotas de acordo com a forma que o usuário pretende seguir o trajeto (CASTRO; TEDESCO, 2014).

\subsection{WAZE}

Considerado o aplicativo que revolucionou a criação de sistemas de recomendação de rotas por incorporar o aspecto colaborativo das redes sociais, o Waze também é um dos aplicativos mais populares do mundo (CASTRO; TEDESCO, 2014).

O aplicativo foi avaliado por mais de três milhões de pessoas e possui uma média de 4.6 estrelas na Google Play. Ele permite que seus usuários possam editar os mapas, informando mudanças de sentido de vias, acidentes e obras públicas, bem como visualizar o posicionamento de outros usuários. Cada usuário possui um perfil, com suas preferências e círculo de relacionamentos, sendo representado por um avatar. A plataforma encoraja a participação dos membros ao premiá-los com novos avatares na medida em que interagem com o Waze e outros usuários, garantindo que o sistema de mapas esteja sempre atualizado (CASTRO; TEDESCO, 2014).

\section{Sistema: Search Class}

O sistema foi desenvolvido utilizando a ferramenta Eclipse ADT 23.0.2 e Android SDK Manager para desenvolvimento mobile, NetBeans IDE 7.4 para desenvolvimento das páginas do servidor Web e a API Google Maps V2 para mapeamento e criação de rotas. Este servidor Web utilizado foi alocado em uma máquina com sistema operacional Linux, Apache para configuração do servidor, MySQL como banco de dados, sendo acessado localmente e através de um endereço válido de internet.

O objetivo do sistema é, a partir de uma interação, guiar o usuário pelo campus da universidade mostrando a ele o caminho mais curto até a sala em que sua turma está assistindo aula.

Essa interação com o usuário é feita a partir do aplicativo instalado no dispositivo móvel, inicialmente com plataforma Android, que deve obter os dados para que seja possível descobrir para onde o usuário deve se encaminhar.

Entretanto, o armazenamento de todas as informações referentes a todos os dados de uma universidade, bem como o cálculo de rotas, poderiam tornar a aplicação inviável de ser executada nos próprios dispositivos móveis, considerando a limitação destes dispositivos em relação à memória disponível, bateria e ao seu poder de processamento em comparação com os computadores pessoais atuais.

Para isso, foi desenvolvido um servidor Web, complementar ao sistema presente nos dispositivos móveis, para persistência dos dados referentes às turmas, horários e salas, bem como a realização dos cálculos das rotas.

Contudo, para a geração de rotas é necessário que os pontos principais do local assim como suas ligações sejam mapeados para criação dos caminhos. Como este mapeamento não está disponível para inúmeras 
propriedades particulares e é muito complicado em locais fechados como prédios, por exemplo, foi desenvolvido um aplicativo denominado "Mapeador" com o objetivo de realizar estes mapeamentos.

Este sistema composto por todas as funcionalidades supracitadas juntamente com os ciclos de comunicação entre os módulos foi denominado Search Class (FIG. 2) e cada um de seus módulos serão explicados nas próximas subseções.

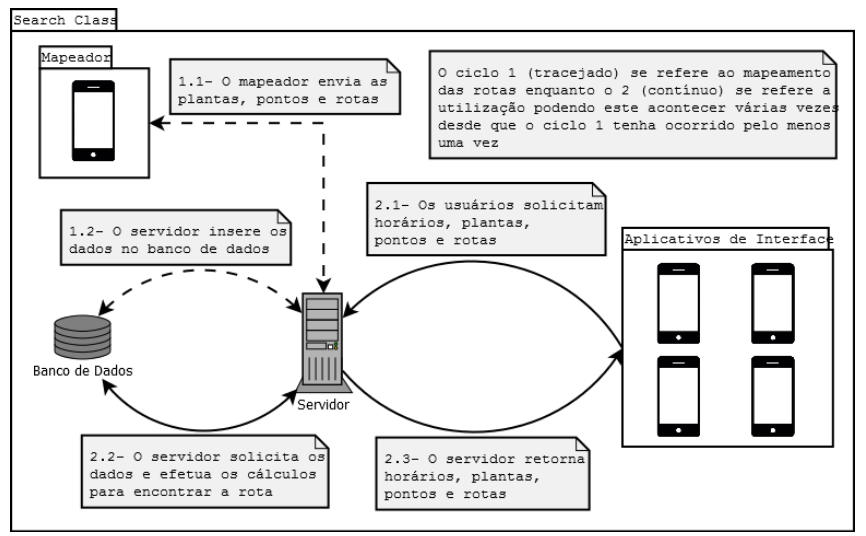

Figura 2 - Ciclos de comunicação entre os módulos do sistema Search Class.

\subsection{MAPEADOR}

O Mapeador é um aplicativo mobile e foi criado com o objetivo de mapear qualquer local para possibilitar a criação de rotas no servidor Web.

Ele utiliza uma lógica própria direcionada para o armazenamento de coordenadas GPS, a montagem plantas e a criação de rotas conforme a necessidade do local. Para isso, utiliza as funcionalidades presentes na API Google Maps V2.

Todo o mapeamento feito é armazenado na memória interna do aparelho mobile até sua finalização. Após ele ser finalizado, os dados podem ser enviados para o servidor Web, onde são inseridos no banco de dados para serem utilizados sempre que necessário pelo aplicativo de interface.
Pensando na economia de memória do aparelho mobile, o Mapeador possui uma opção de receber os dados do servidor Web. Assim, não há a necessidade de o mapeamento permanecer na memória interna, uma vez que o ele esteja no servidor. Caso haja a necessidade de alterá-lo, basta fazer o download dos dados atuais, realizar as alterações e enviá-las novamente para o servidor.

Além de ser capaz de armazenar pontos importantes e criar rotas em lugares que não possuem este mapeamento do Google, o Mapeador é capaz de criar plantas (FIG. 3) de qualquer lugar. Esta criação de plantas pode ser utilizada principalmente para o mapeamento de rotas em lugares fechados como prédios, museus e shoppings, por exemplo, para serem exibidos ao usuário do aplicativo de interface.

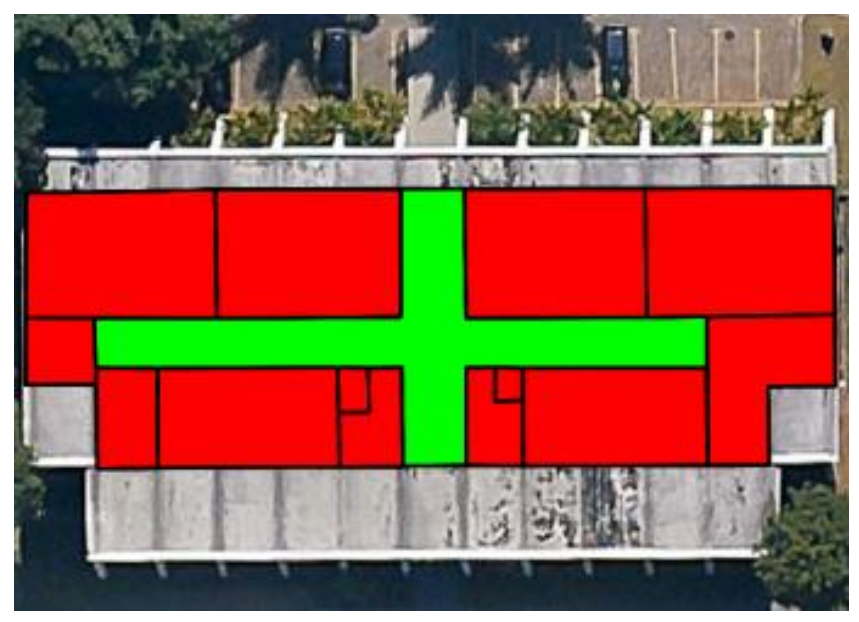

Figura 3 - Planta do primeiro andar do Bloco A4 do Centro Universitário de Belo Horizonte (UNIBH).

Dessa forma, o usuário do aplicativo de interface além de poder visualizar as rotas pelo campus, pode também visualizar a planta com seus principais pontos e as rotas presentes em cada andar dos prédios.

\subsection{SERVIDOR Web}

O servidor Web é responsável por gerenciar os dados, sendo ele o módulo central entre o Banco de Dados, o Mapeador e o Aplicativo de Interface. 
Este servidor Web é responsável por todas as inserções no banco de dados, cálculo de rotas e envio de dados para os dispositivos mobile.

Dessa forma, os usuários tem o aplicativo de interface como única aplicação, sem que haja a preocupação de atualizações nela por conta das mudanças de horários, pois todas as informações estariam sendo alocadas pela universidade no servidor.

Além da gerencia dos dados, este servidor também é responsável por, a partir da localização atual do usuário do aplicativo de interface ou um ponto selecionado no mapa, calcular a menor rota até o local onde a turma escolhida pelo usuário terá aula. Esse cálculo é feito por meio do Algoritmo de Dijkstra que, desenvolvido por Edsger Wybe Dijkstra em meados de 1959, tem como objetivo encontrar o menor caminho entre vértices de um grafo simples (NETTO, 1996; BARROS; PAMBOUKIAN; ZAMBONI, 2007).

Para implementação do algoritmo, é necessário definir o ponto de origem e o destino. Em seguida, todos os vértices do grafo (FIG. 4), exceto o vértice de origem que é iniciado com um valor nulo, são iniciados com valor infinito e são gerenciados entre duas listas, uma lista de vértices marcados e uma lista de vértices desmarcados. Também são necessários dois vetores, um para guardar os comprimentos acumulados e outro para guardar o vértice anterior. Então, para cada vértice, o algoritmo vai verificar todas as conexões do vértice que ainda não estão na lista de vértices marcados, calcular as distâncias acumuladas das conexões disponíveis e identificar entre essas conexões qual apresenta a menor distância acumulada, adicionando-a na lista adequada (NETTO, 1996; BARROS; PAMBOUKIAN; ZAMBONI, 2007).

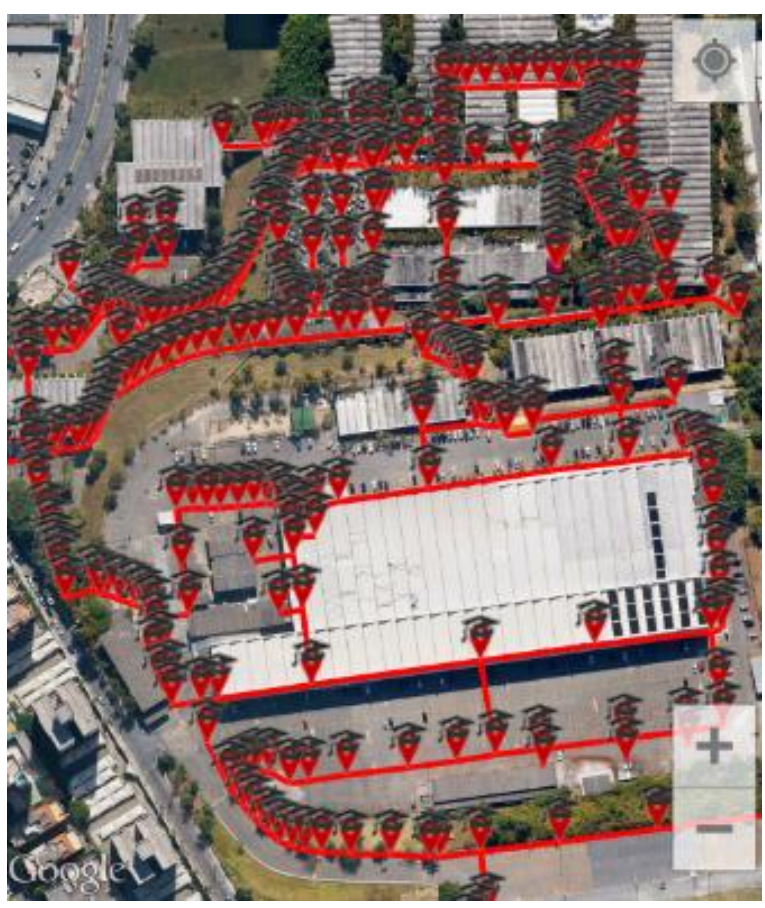

Figura 4 - Grafo criado para o Centro Universitário de Belo Horizonte (UNIBH).

$\mathrm{Na}$ Figura 4, os vértices são os ícones de marcação, no estilo Google Maps, contendo um logotipo do Search Class, e as arestas são as linhas vermelhas que interconectam esses vértices, representando o grafo sobre o qual o algoritmo de Dijkstra realiza o processamento. A implementação da fila de prioridades em um heap assegura ótimo desempenho ao algoritmo (NETTO, 1996; ZIVIANI, 2011).

Como o ponto de origem recebido pode não ter sido mapeado, é feito um cálculo da Distância Euclidiana do ponto de origem recebido e os demais pontos mapeados para que o ponto mapeado mais próximo seja utilizado como ponto de origem. Isso faz com que todo o processamento de rotas e buscas no banco de dados seja realizado somente no servidor que, depois de realizar os cálculos, devolve os resultados para o aplicativo de interface.

\subsection{ApLiCATIVO DE INTERFACE}

O Aplicativo de Interface é responsável por interagir diretamente com o usuário, obter as informações que 
o servidor Web necessita para encontrar o local onde a turma do usuário terá aula e exibir o menor caminho até a respectiva sala a partir do local onde o usuário está localizado.

Como toda informação passada pelo usuário gera uma nova busca no servidor, que por sua vez deve enviar os resultados dessa busca para que o aplicativo de interface obtenha novas informações, cria-se uma grande dependência entre os dois módulos.

Embora essa dependência faça com que a falta de conexão à Internet impossibilite a utilização do aplicativo, ela também trás como principal vantagem o fato que qualquer expansão ou alteração dos locais abordados pelo aplicativo e dos horários não necessitem que sejam feitas atualizações no sistema todo, bastando apenas alterar as regras de negócio gerenciadas no servidor.

A utilização de dados armazenados em um servidor remoto torna o aplicativo fácil de ser adaptado a outro campus, visto que a utilização da ferramenta em diferentes campi depende somente do mapeamento destes novos campi, permitindo que o aplicativo seja utilizado sem a necessidade de alteração.

Considerando uma adaptabilidade do sistema a outros locais não universitários (prédios, museus, shoppings, entre outros), seria necessária, além do mapeamento do local, uma adaptação no aplicativo de interface e nas regras de negócio presente no servidor, contudo seus objetivos e formas de comunicação se manteriam, tornando o processo mais simplificado.

\section{IMPLANTAÇÃO}

Foi desenvolvido e implantado o sistema Search Class no Centro Universitário de Belo Horizonte. O Aplicativo de Interface foi desenvolvido somente para Android e denominado Busca Sala (FIG. 5), disponibilizado em agosto de 2014 na Google Play pela Ânima Educação e utilizado pelos alunos da instituição do campus Estoril ao longo do $2^{\circ}$ semestre do respectivo ano.

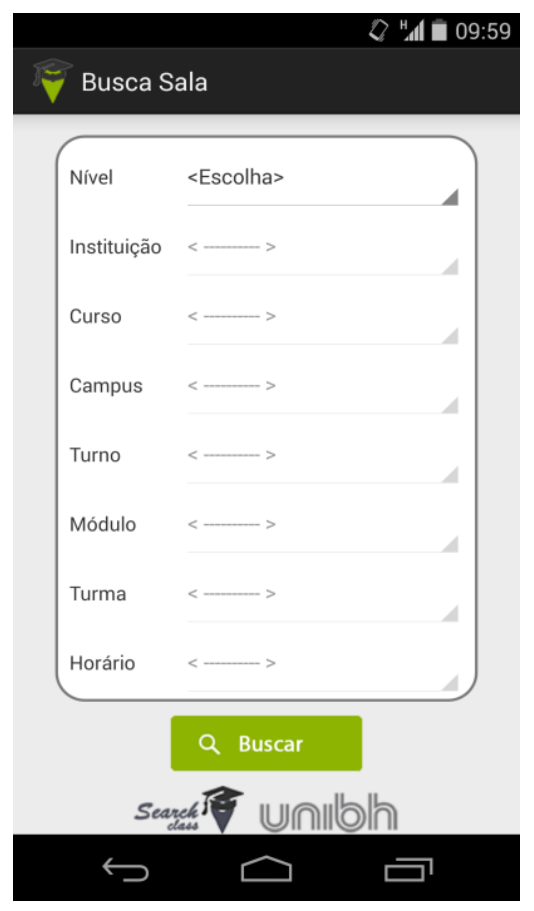

Figura 5 - Aplicativo Busca Sala em sua tela de abertura.

Foram necessárias algumas alterações entre a primeira versão desenvolvida do sistema e a implantada para que o sistema pudesse se adequar aos padrões aceitos pela instituição. Contudo o desenvolvimento modular do sistema contribuiu para facilitar o processo.

O Busca Sala é a interface de comunicação com os usuários. Para cada filtro, o aplicativo aciona o servidor Web para que este busque as informações no banco de dados e as retorne ao usuário.

Após os usuários preencherem todos os filtros, os dados são utilizados para buscar as informações sobre a aula e exibi-las ao usuário, assim como a possibilidade de acessar o mapa (FIG. 6).

e-xacta, Belo Horizonte, v. 8, n. 1, p. 117-129. (2015). Editora UNIBH. Disponível em: www.unibh.br/revistas/exacta/ 


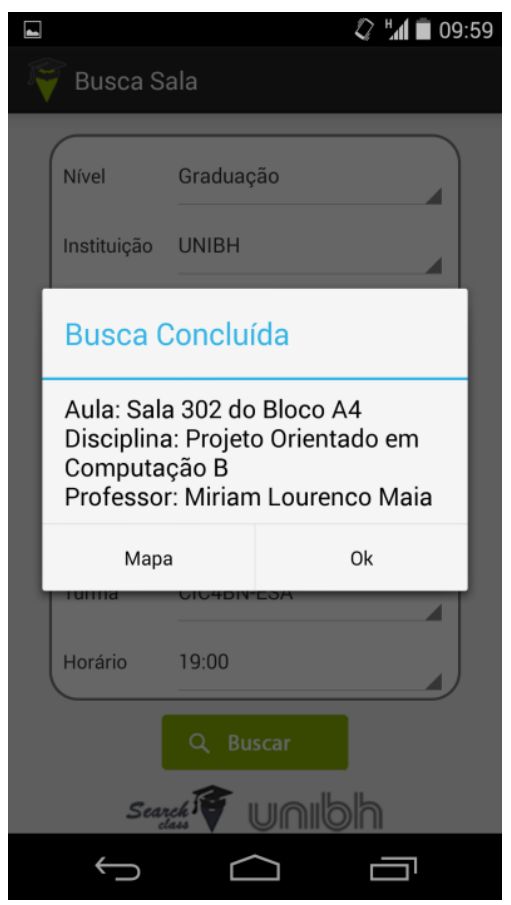

Figura 6 - Aplicativo Busca Sala exibindo o resultado da busca.

No mapa, são apresentados de forma destacada alguns pontos principais na instituição, bem como seus nomes e suas descrições. O usuário tem a possibilidade de escolher um ponto de origem, através de um clique longo no mapa, ou aguardar que sua localização seja automaticamente capturada pelo aplicativo por meio do GPS. A partir da localização, o aplicativo aciona o servidor Web que se encarrega de encontrar o menor caminho até a sala, através do algoritmo de Dijkstra, e devolver ao aplicativo este caminho. Com o recebimento do caminho, o aplicativo se encarrega de exibi-lo ao usuário juntamente com o ponto de destino destacado (FIG. 7).

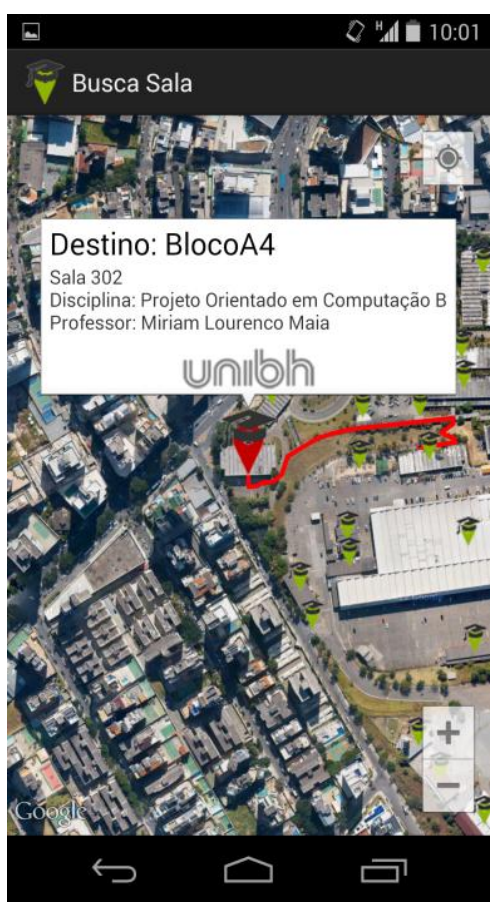

Figura 7 - Rota criada a partir de um ponto de origem escolhido até o local onde a turma selecionada está tendo aula no horário selecionado no dia do acesso.

\subsection{ROTAS INTERNAS}

Embora o sistema tenha obtido uma grande aceitação dos alunos que o utilizaram e também tenha agradado a instituição onde ele foi implantado, segundo seus representantes, ele ainda possuía uma limitação que o impedia de alcançar o objetivo para o qual foi criado: não havia rotas internas.

Sem essas rotas, o aplicativo era capaz de guiar o usuário pelo campus até o prédio onde a sala está, mas ainda não podia guia-lo até sua respectiva sala.

Para atender a esse objetivo foram utilizadas três plantas, referentes aos três andares de um dos blocos da instituição, disponibilizadas pela própria instituição. Essas plantas foram criadas no Mapeador, juntamente com seus pontos principais e todos os caminhos possíveis, para cada andar (FIG. 8), e enviadas devidamente ao servidor Web. 


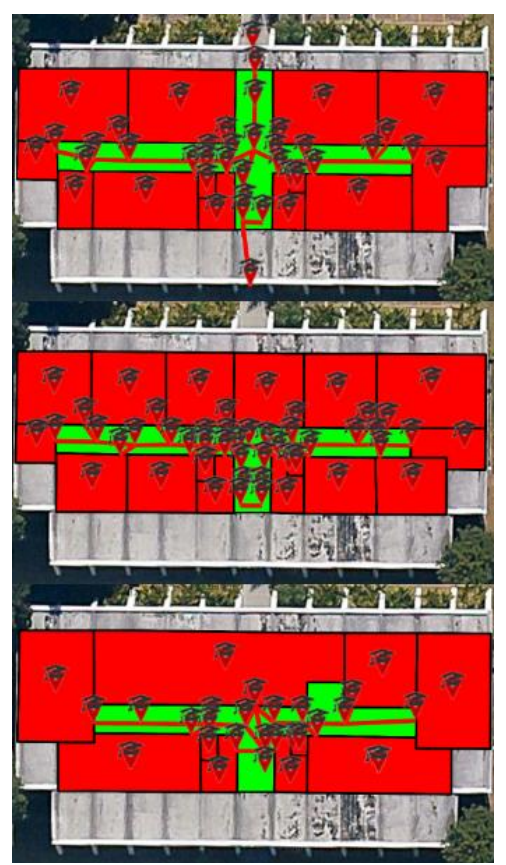

Figura 8 - Plantas, caminhos internos e principais pontos dos três andares do Bloco A4 do Centro Universitário de Belo Horizonte, campus Estoril, criados no Mapeador.

Para receber estes dados e poder exibi-los aos usuários, o Aplicativo de Interface implantado também precisou passar por alterações se adequar a essa necessidade. Embora se limitassem a uma mesma região, as plantas, pontos e caminhos devem ser exibidos de acordo com o andar que seu usuário estiver visualizando.

\section{Testes e Resultados}

Esta seção apresenta os experimentos realizados com o sistema de informação multimídia implementado e discute os principais resultados obtidos, visando demonstrar a avaliação do sistema pelo ponto de vista do usuário e pela acurácia de seu funcionamento.
Pela perspectiva do usuário, foram registrados entre 500 e 1000 downloads do aplicativo e o mesmo obteve média de 4,3 estrelas na avaliação de 34 usuários. Considerando apenas as notas dos 11 usuários que deixaram um comentário sobre sua experiência de utilização, contribuindo com a melhoria do sistema, a média sobe para 5 estrelas, pois os usuários que deram notas inferiores a 5 não se pronunciaram sobre o motivo da nota ou possíveis problemas encontrados em sua experiência.

Para testar a acurácia do sistema foi necessário verificar: a concentração de acessos em relação à quantidade de cursos e blocos de destino das rotas; se as rotas internas e externas se conectavam corretamente; se todas as portas mapeadas poderiam ser alcançadas e; se o sistema optou pela porta mais próxima, caso houvesse mais de uma porta para a mesma sala ou prédio.

Em relação à quantidade de acessos, a FIG. 9 evidencia que mais de $84 \%$ das 3.781 buscas efetivadas com sucesso no segundo semestre de 2014 ficaram concentradas em torno de $50 \%$ dos cursos da instituição. Em todos os testes realizados no aplicativo de interface, ele foi capaz de ligar a rota exibida pela versão implantada à rota interna ao bloco, exibindo cada caminho e os pontos principais de acordo com o andar exibido (FIG. 10). 


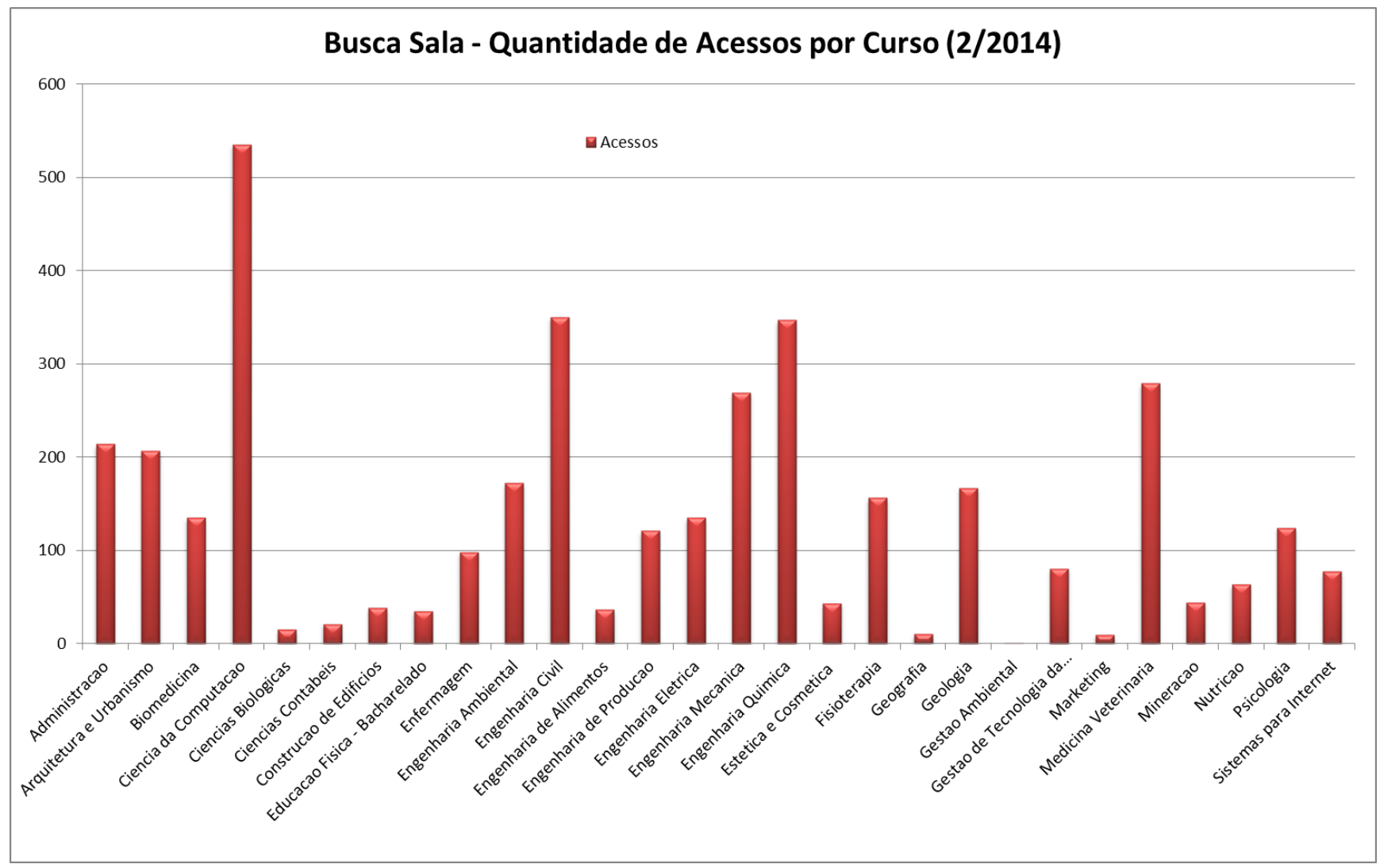

Figura 9 - Concentração da quantidade de acessos agrupada por curso no segundo semestre de 2014.

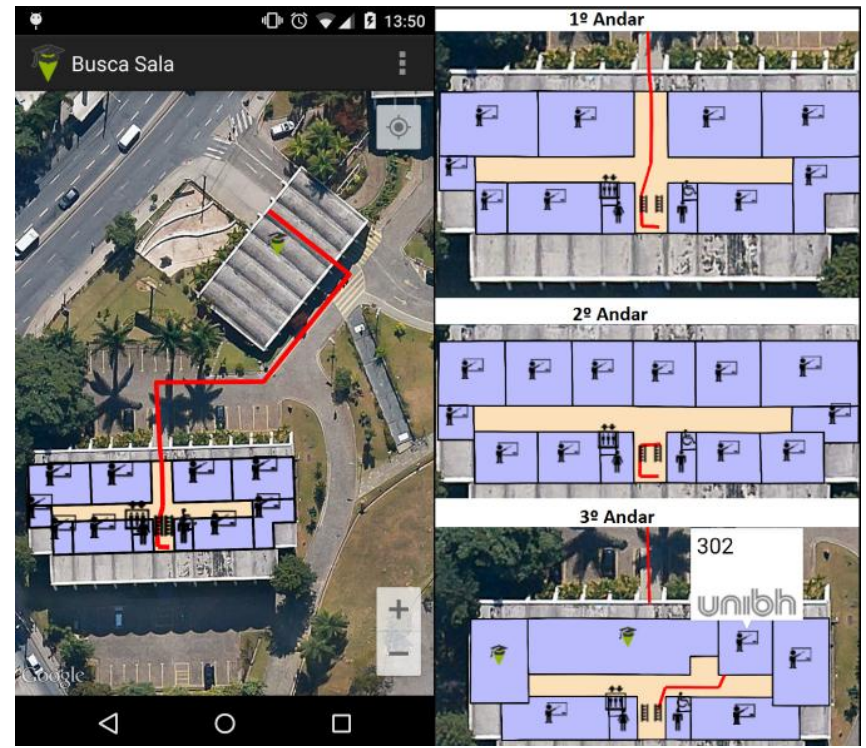

Figura 10 - Rota de um ponto qualquer da instituição até o bloco A4 (esquerda) e as plantas, principais pontos e rotas internas, de cada andar do bloco até a sala 302 (direita). 


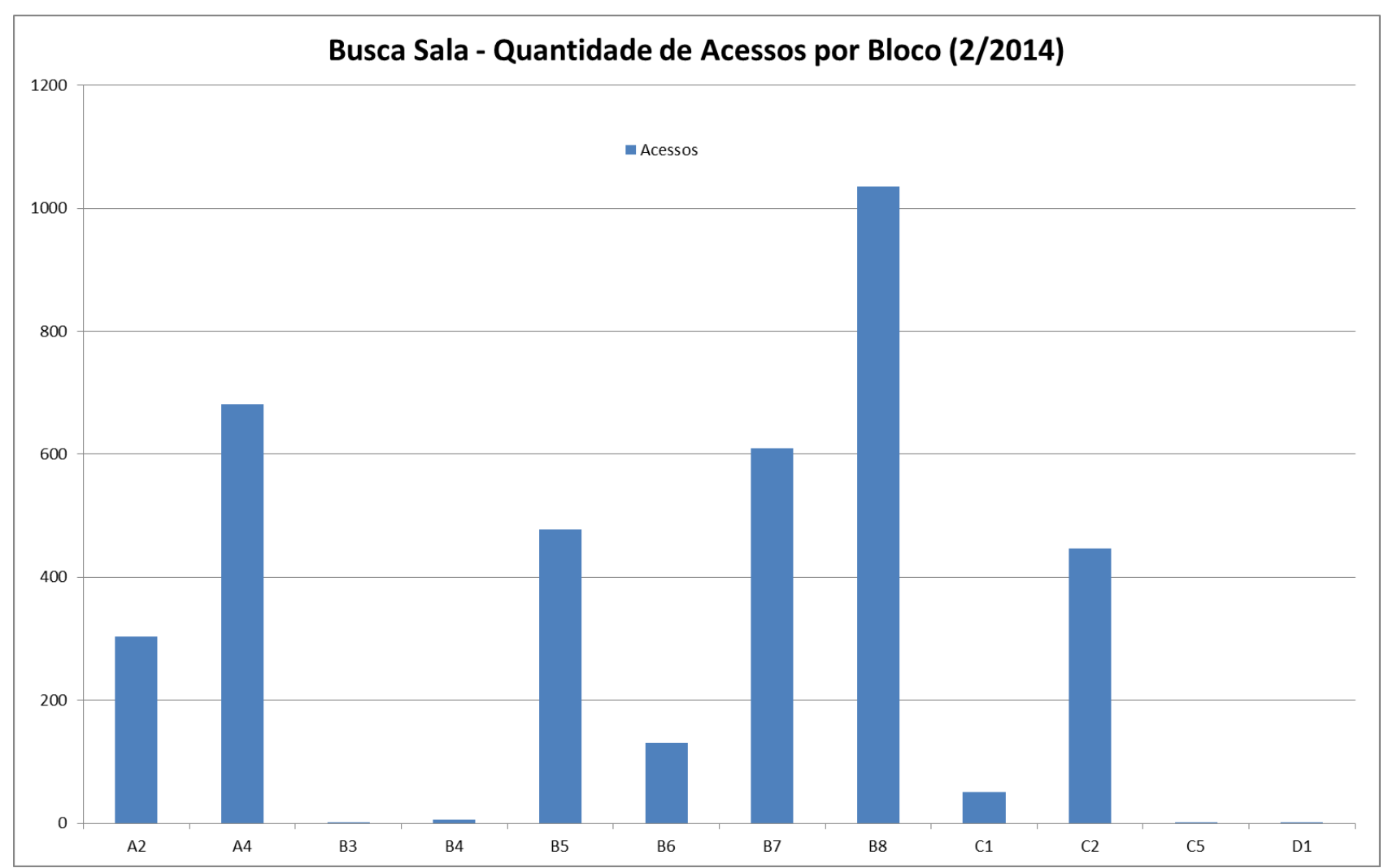

Figura 11 - Concentração da quantidade de acessos agrupada por curso no segundo semestre de 2014.

Analisou-se, também, a concentração da quantidade dos acessos em torno dos blocos de salas do UnibH, conforme ilustrado na FIG.a 11, para entender quais os destinos de rotas mais acessados a fim de estudar, em futuras ações de marketing, se a menores rotas computadas sobre o grafo do sistema são, realmente, as melhores e menores rotas existentes no espaço físico, bem como divulgar e potencializar o uso do aplicativo nos destinos de rotas menos efetivados. Percebe-se que apenas $25 \%$ dos blocos tiveram mais de $61 \%$ das buscas de rotas efetivadas.

Uma observação importante detectada durante os testes é que, a versão desenvolvida e testada do algoritmo de Dijkstra não possui sensibilidade com a mudança entre os andares de um prédio. Para que ele busque uma sala em um andar específico não pode haver nenhuma outra mapeada com o mesmo nome. Caso haja, o algoritmo entende que elas são a mesma sala, mesmo que estejam em andares diferentes, ocasionando a criação de rotas inexistentes.
Corrigidos todos os problemas e observações no mapeamento o algoritmo desenvolvido foi capaz de criar uma rota até a porta mais próxima do prédio e da sala em todos os testes.

\section{Conclusão}

Com base no que foi apresentado neste artigo, o sistema Search Class é capaz de direcionar seu usuário a uma sala dentro de um prédio na universidade a partir de qualquer ponto de origem, considerando que, para pontos fora da universidade, a própria API Google Maps V2 utilizada retorna o melhor caminho, bem como os outros aplicativos apresentados.

Além disso, o sistema se mostrou eficiente para ser adaptado, considerando a facilidade em realizar as alterações que foram necessárias entre a primeira versão desenvolvida e a versão implantada. Assim, o 
sistema pode ser adequado a outros ambientes, conforme comprovado com sua implantação e descrito anteriormente, tendo o mapeamento do local como a etapa mais demorada do processo de adaptação.

Dessa forma, pode-se concluir que o sistema Search Class atende aos objetivos iniciais pelos quais foi desenvolvido, tendo uma boa avaliação de seus usuários e da instituição onde foi implantado considerando a avaliação dos sistemas similares apresentados, além de se mostrar habilitado a se adequar a vários ambientes sem grandes alterações.

Objetivando o aprimoramento do sistema, se deve adaptar o algoritmo de Dijkstra tornando-o capaz de distinguir salas com o mesmo nome em andares diferentes. Essa mudança facilitará o mapeamento que não mais precisará de um identificador único para cada sala no prédio, tal identificador poderá ser por andar.
Outra mudança importante é agregar ao sistema as características dos sistemas similares apresentados na seção 2 deste artigo, tornando-o colaborativo, o que pode trazer informações importantes também para a instituição através das informações inseridas pelos usuários.

\section{AGRADECIMENTOS}

Os autores agradecem ao Prof. Bráulio Roberto Gonçalves Marinho Couto e ao Líder de Sistemas Alexandre Ubaldo Ferreira de Carvalho, pela dedicação e grande ajuda; ao Centro Universitário de Belo Horizonte (UNIBH) e ao Grupo Ânima, pela valiosa oportunidade e experiência; e aos demais Professores e Alunos que contribuíram para o enriquecimento deste projeto com opiniões diversas que contribuíram com a melhoria do sistema.

\section{REFERÊNCIAS}

BALDI, L. M. Desenvolvimento de uma Aplicação para Localização de Fast Food. Monografia, Especialização Tecnologia Java, Programa de PósGraduação em Tecnologia da Informação, Centro Federal de Educação Tecnológica do Paraná, Curitiba, 2011.

BALTZAN, P.; PHILLIPS, A. Sistema de Informação. McGraw Hill Brasil, AMGH Editora Ltda., 384 páginas, Porto Alegre, Rio Grande do Sul, 2012.

BARROS, E. A. R.; PAMBOUKIAN, S. V. D.; ZAMBONI, Lincoln C. Algoritmo de Dijkstra: Apoio Didático e Multidisciplinar na Implementação, Simulação e Utilização Computacional. International Conference on Engineering and Computer Education (ICECE), São Paulo, 11-14 Março, 2007.

BERNARDI, J. V. E.; LANDIM, P. M. B. Aplicação do Sistema de Posicionamento Global (GPS) na Coleta de Dados. UNESP, Departamento de Geologia Aplicada (IGCE), Laboratório de Geomatemática, Texto Didático 10, Rio Claro, 2002.
CASTRO, M. F.; TEDESCO, P. Aplicação de Conceitos de Wayfinding em Interfaces Mobile de Recomendação de Rota. In: X Simpósio Brasileiro de Sistemas de Informação, 2014, Londrina, Paraná. Aplicação de Conceitos de Wayfinding em Interfaces Mobile de Recomendação de Rota. 2014, Universidade Federal de Pernambuco (UFPE), Centro de Informática, Recife, Pernambuco. Disponível em www.lbd.dcc.ufmg.br/colecoes/sbsi/2014/0040.pdf. Acesso em 08 de maio de 2015.

CORREIA, A. G. S. Aplicações e Serviços Baseados em Localização. Pontifícia Universidade Católica do Rio de Janeiro, Centro Técnico Científico, Departamento de Informática, Programa de Mestrado, Rio de Janeiro, Novembro, 2004.

FIGUEIREDO, C. M. S.; NAKAMURA, E. Computação Móvel: Novas Oportunidades e Novos Desafios. T\&C Amazônia, Ano 1, no 2, Junho, 2003. FIORESE, Virgilio; Wireless Introdução às Redes de Telecomunicação Móveis Celulares. Editora Brasport, 344 páginas, Rio de Janeiro, 2005. 
LECHETA, R. R. Google Android: Aprenda a Criar Aplicações para Dispositivos Móveis com 0 Android SDK. 3 $3^{\text {a }}$ Edição, Editora Novatec Editora Ltda., 821 páginas, São Paulo, 2013.

MATEUS, G. R.; LOUREIRO, A. A. F. Introdução à Computação Móvel. Departamento de Ciência da Computação da UFMG, 1998.

NETTO, P. O. B. Grafos Teoria Modelos Algoritmos. $2^{\underline{a}}$ edição, Editora Edgard Blücher Ltda., 304 páginas, São Paulo, 1996.
PEREIRA, L. C. O.; LOURENÇO, M. S. Android para Desenvolvedores. Editora Brasport Livros e Multimidia Ltda., 240 páginas, Rio de Janeiro 2009.

ZIVIANI, N. Projeto de Algoritmos com Implementações em Pascal e C. $3^{\text {a }}$ edição, Editora Cengage Learning, 639 páginas, São Paulo, 2011. 